\title{
Editorial \\ Colon Capsule Endoscopy as a Diagnostic Adjunct in Patients with Symptoms from the Lower Gastrointestinal Tract
}

\author{
Thomas Bjørsum-Meyer ${ }^{1,2, *}$, Gunnar Baatrup ${ }^{1,2}$ and Anastasios Koulaouzidis ${ }^{3}$ (D) \\ 1 Department of Surgery, Odense University Hospital, 5700 Svendborg, Denmark; gunnar.baatrup@rsyd.dk \\ 2 Department of Clinical Research, University of Southern Denmark, 5230 Odense M, Denmark \\ 3 Department of Social Medicine \& Public Health, Pomeranian Medical University, 70-204 Szczecin, Poland; \\ akoulaouzidis@hotmail.com \\ * Correspondence: thomas.bjoersum-meyer@rsyd.dk; Tel.: +45-27896080
}

\section{check for}

updates

Citation: Bjørsum-Meyer, T.; Baatrup, G.; Koulaouzidis, A. Colon Capsule Endoscopy as a Diagnostic Adjunct in Patients with Symptoms from the Lower Gastrointestinal Tract. Diagnostics 2021, 11, 1671. https:// doi.org/10.3390/diagnostics11091671

Received: 25 August 2021

Accepted: 9 September 2021

Published: 13 September 2021

Publisher's Note: MDPI stays neutral with regard to jurisdictional claims in published maps and institutional affiliations.

Copyright: (c) 2021 by the authors. Licensee MDPI, Basel, Switzerland. This article is an open access article distributed under the terms and conditions of the Creative Commons Attribution (CC BY) license (https:/ / creativecommons.org/licenses/by/ $4.0 /)$.
Prompted by the core idea of wireless capsule endoscopy as a painless gastrointestinal examination, and the easy adoption of small bowel capsule endoscopy, the armamentarium of the capsule-based imaging platforms has grown to include colon capsule devices as well [1]. Fueled to an extent by technology can-do and manufacturers' targets, this process seems to have ignored advice from clinicians as well as aspirations for precision medicine, i.e., the need-do and need-have of such devices. We have been handed a tool with certain specifications and the initial effort was consumed in an a priori lost fight, i.e., to prove that CCE has equivalent clinical validity to colonoscopy. Paradoxically, we have to thank a major epidemiologic crisis for exploring alternative uses of this tool, e.g., as part of a stepped triage pathway. In a recent meta-analysis by Pin-Vieito et al. on the performance of a fecal immunochemical test (FIT) in symptomatic patients presenting to primary health care, they concluded that the FIT is the test of choice for patients with new-onset complaints from the lower gastrointestinal (GI) tract [2]. The triage with the FIT has undoubtedly high potential although more data are warranted, especially about cut-off levels and consequences. However, we find a wide adoption of this strategy in general practice potentially hazardous and express our concern. More studies have reported poor detection rates of the FIT for Union for International Cancer Control (UICC) stage I colorectal cancer (CRC) and specifically T1 cancers in screening settings $[3,4]$. The same findings must be suspected in symptomatic patients. In a recent study in a screening population, Niedermaier et al. found that decreasing the FIT cut-off value from $40 \mu \mathrm{g} / \mathrm{g}$ to $10 \mu \mathrm{g} / \mathrm{g}$ increased the sensitivity from $37 \%$ to $61 \%$ [5]. On the other hand, such a change would increase the number of colonoscopies almost threefold. We need to find a delicate balance between not missing cancers without overburdening already tied-up endoscopy units. Pin-Vieito et al. raise a very important yet unsettled obstacle: how do we decrease the number of FIT negative interval cancers without deluging overburdened endoscopy units? In our opinion, we need a sustainable adjunct to the FIT in order not to cut corners and without exhausting hospital services. We need a diagnostic modality which can be performed in primary health care. Colon capsule endoscopy (CCE) might be part of such a solution/pathway. CCE got wind in its sails during the COVID-19 pandemic as it can be performed in out-patient clinics with minimal contact with health care professionals and other patients [6]. Several studies have reported CCE to have sensitivity and specificity for detecting CRC and significant polyps (cancer precursors) similar to or better than conventional colonoscopy (CC) $[7,8]$.

In a recent UK study, the diagnostic performance of FIT was evaluated in a population with low-risk symptoms of CRC in primary care and found the FIT to perform very well in triage patients [9]. The authors reported a sensitivity and specificity for CRC of $84.3 \%$ and $85.0 \%$, respectively, at a cut-off value of $10 \mu \mathrm{g} \mathrm{Hb} / \mathrm{g}$ feces. They estimated that a FIT value of $37 \mu \mathrm{g} \mathrm{Hb} / \mathrm{g}$ feces in an individual corresponds to a CRC risk of $3 \%$. This equals the risk 
for which an urgent colonoscopy is warranted according to the NICE recommendations (https:/ / www.nice.org.uk/guidance/NG12, accessed on 10 August 2021). Based on these estimates, we have proposed a flowchart for handling patients presenting at their general practitioner (GP) with symptoms from the lower GI based on the result of the FIT (Figure 1).

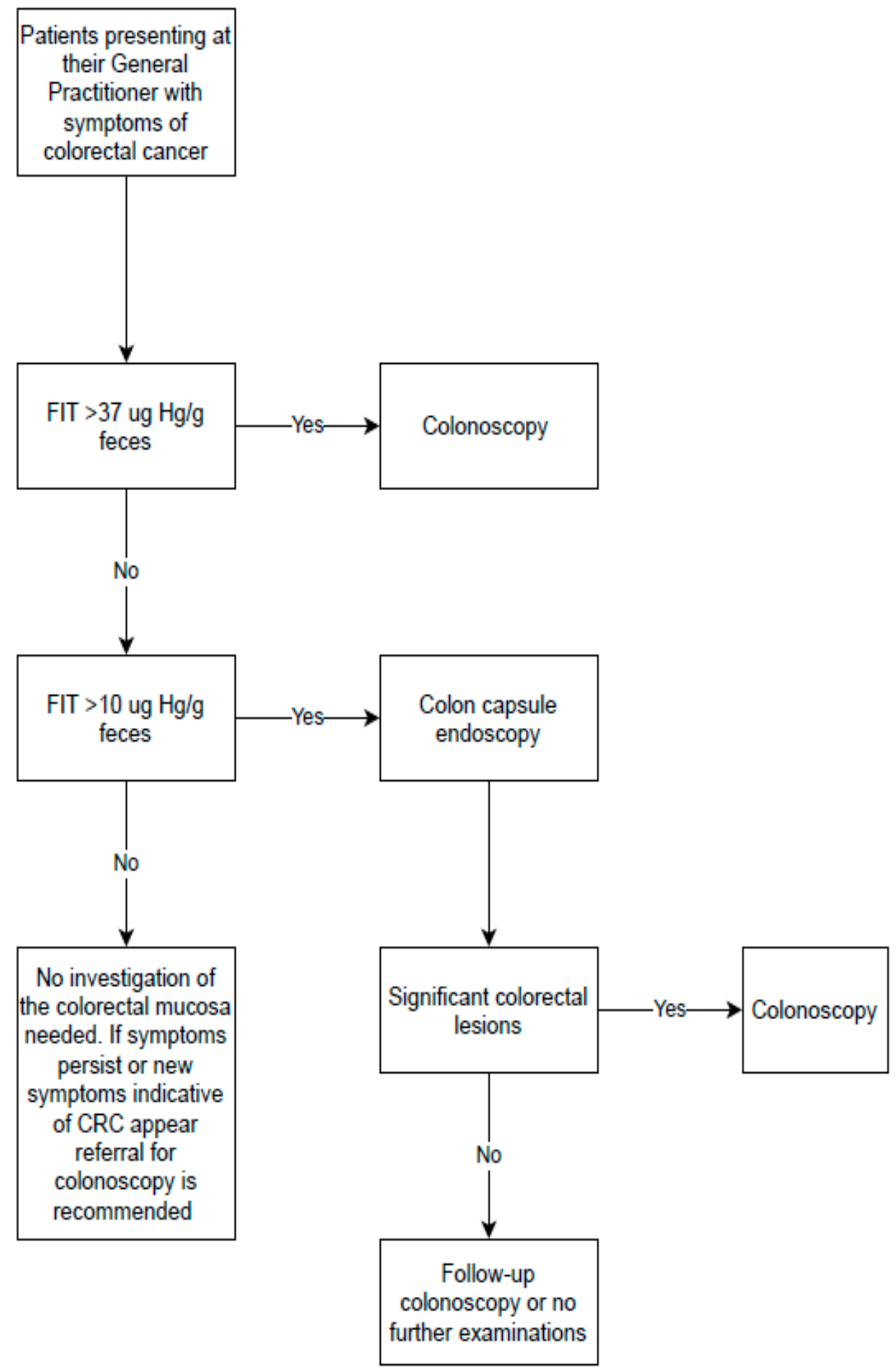

Figure 1. Suggested flow of patients presenting with symptoms of colorectal cancer at their general practitioner. Definitions: significant colorectal lesions: suspected cancer or any polyps $>9 \mathrm{~mm}$. 
CCE has shortcomings that need to be mentioned to understand its current position as a diagnostic tool. Before CCE, extensive bowel preparation is required to achieve an adequate visualization of the bowel mucosa as gas insufflation and washing/suction are not options, compared to CC. Further improvements in bowel cleansing regimens for $\mathrm{CCE}$ are requisite to make it an equal diagnostic alternative to CC. Apart from requiring considerable health care resources, CC is also unpleasant for patients with risks of severe complications in terms of bowel perforation and post-polypectomy bleeding. Not least, the procedure often induces embarrassment and discomfort in the patients. In our opinion, we are in urgent need of a patient-friendly, out-of-hospital diagnostic modality which can be initiated and concluded by the GP to alleviate overburdened endoscopic units without increasing the rates of missed significant pathology. Due to recent advances in artificial intelligence (AI)-assisted CCE, the tool we need seems just around the corner. AIbased systems have been developed and found to automatically detect colorectal neoplasia with high accuracy [10]. AI-based algorithms for size estimation and characterization of colorectal neoplasia are under development. They are expected to be implemented very soon in an automatized analysis of CCE videos, providing a result within minutes after egestion of the colon capsule. This would enable the GP to reassure the patients or refer to $\mathrm{CC}$ for polyp removal or urgent biopsy in due time. As most symptomatic patients leave endoscopic units after a colonoscopy without achieving a clear cause of their symptoms, there is an obvious need for improvement to allocate patients with lower GI symptoms to the proper examination without unnecessary delay. Despite a wider adoption of CCE hastened by the COVID-19 pandemic, CC remains the preferred diagnostic modality in screening settings, although the CCE performance in bowel cancer screening is currently under evaluation in an ongoing clinical trial [11].

Author Contributions: Conceptualization, T.B.-M., G.B. and A.K.; writing-original draft preparation, T.B.-M. and A.K.; writing-review and editing, G.B. and A.K. All authors have read and agreed to the published version of the manuscript.

Funding: This research received no external funding.

Institutional Review Board Statement: Not applicable.

Informed Consent Statement: Not applicable.

Data Availability Statement: Not applicable.

Conflicts of Interest: A.K. is guest editor on the Special Issue "Advancements in Colonoscopy" in Diagnostics. A.K. is consultant for Jinshan. He is director of iCERV Ltd and cofounder of AJM Medicaps Ltd. He has received a GivenImaging Ltd-ESGE grant, and material support for clinical research from SynMed/Intromedic. In the last ten years, he has received honoraria and lecture fees from Jinshan, FalkPharma UK and Ferring. He has also received educational travel support from Aquilant, Jinshan, FalkPharma, Almirall and Ferring, and has participated in advisory board meetings for Tillots, Ankon and FalkPharma UK.

\section{References}

1. Iddan, G.; Meron, G.; Glukhovsky, A.; Swain, P. Wireless capsule endoscopy. Nature 2000, 405, 417. [CrossRef] [PubMed]

2. Pin-Vieito, N.; Tejido-Sandoval, C.; de Vicente-Bielza, N.; Sánchez-Gómez, C.; Cubiella, J. Faecal immunochemical tests safely enhance rational use of resources during the assessment of suspected symptomatic colorectal cancer in primary care: Systematic review and meta-analysis. Gut 2021. [CrossRef] [PubMed]

3. Morikawa, T.; Kato, J.; Yamaji, Y.; Wada, R.; Mitsushima, T.; Shiratori, Y. A comparison of the immunochemical fecal occult blood test and total colonoscopy in the asymptomatic population. Gastroenterology 2005, 129, 422-428. [CrossRef] [PubMed]

4. Xie, Y.-H.; Gao, Q.-Y.; Cai, G.-X.; Sun, X.-M.; Zou, T.-H.; Chen, H.-M.; Yu, S.-Y.; Qiu, Y.-W.; Gu, W.-Q.; Chen, X.-Y.; et al. Fecal Clostridium symbiosum for Noninvasive Detection of Early and Advanced Colorectal Cancer: Test and Validation Studies. EBioMedicine 2017, 25, 32-40. [CrossRef] [PubMed]

5. Niedermaier, T.; Tikk, K.; Gies, A.; Bieck, S.; Brenner, H. Sensitivity of Fecal Immunochemical Test for Colorectal Cancer Detection Differs According to Stage and Location. Clin. Gastroenterol. Hepatol. 2020, 18, 2920-2928.e6. [CrossRef] [PubMed]

6. MacLeod, C.; Wilson, P.; Watson, A.J.M. Colon capsule endoscopy: An innovative method for detecting colorectal pathology during the COVID-19 pandemic? Colorectal Dis. 2020, 22, 621-624. [CrossRef] [PubMed] 
7. Kjølhede, T.; Ølholm, A.M.; Kaalby, L.; Kidholm, K.; Qvist, N.; Baatrup, G. Diagnostic accuracy of capsule endoscopy compared with colonoscopy for polyp detection: Systematic review and meta-analyses. Laryngo-Rhino-Otol. 2020, 53, 713-721. [CrossRef] [PubMed]

8. Kobaek-Larsen, M.; Kroijer, R.; Dyrvig, A.-K.; Buijs, M.M.; Steele, R.J.C.; Qvist, N.; Baatrup, G. Back-to-back colon capsule endoscopy and optical colonoscopy in colorectal cancer screening individuals. Color. Dis. 2018, 20. [CrossRef] [PubMed]

9. Bailey, S.E.R.; Abel, G.A.; Atkins, A.; Byford, R.; Davies, S.-J.; Mays, J.; McDonald, T.J.; Miller, J.; Neck, C.; Renninson, J.; et al. Diagnostic performance of a faecal immunochemical test for patients with low-risk symptoms of colorectal cancer in primary care: An evaluation in the South West of England. Br. J. Cancer 2021, 124, 1231-1236. [CrossRef] [PubMed]

10. Yamada, A.; Niikura, R.; Otani, K.; Aoki, T.; Koike, K. Automatic detection of colorectal neoplasia in wireless colon capsule endoscopic images using a deep convolutional neural network. Endoscopy 2020, 53, 832-836. [CrossRef] [PubMed]

11. Kaalby, L.; Deding, U.; Kobaek-Larsen, M.; Havshoi, A.-L.V.; Zimmermann-Nielsen, E.; Thygesen, M.K.; Kroeijer, R.; BjørsumMeyer, T.; Baatrup, G. Colon capsule endoscopy in colorectal cancer screening: A randomised controlled trial. BMJ Open Gastroenterol. 2020, 7, e000411. [CrossRef] [PubMed] 